\title{
The Threshold of Abstraction in Beginning Design Pedagogy
}

\author{
Stephen Temple $\mathbb{0}$ \\ Department of Architecture, University of Texas at San Antonio, San Antonio, USA,
}

Received: November 4th 2020, Accepted: November 14th 2020

Refer: Temple, S., (2020), The Threshold of Abstraction in Beginning Design Pedagogy, Journal of Design Studio, V.2, N.2, pp 101-110,

ORCID: 0000-0002-0926-1165

DOI: $10.46474 /$ jds. 820784 https://doi.org/10.46474/jds. 820784

\begin{abstract}
By immediately being asked to work abstractly, beginning design students are investigating architecture through a pedagogy taken-for-granted by its instructors. To abstract something is to draw it out of the concrete, and unless a student is looking for this displacement, they will become disconcerted, struggle, and become lost to the design process. Abstract operations of design, when presented out of step with student self-development, can mislead and distort experience. This essay defines a student's encounter with abstraction as a threshold concept within the transformative journey of design student self-development. Writings about abstraction in artistic production by Sigfried Gidieon and Rudolph Arnheim define abstraction and provide a basis for critique of abstraction as a threshold concept in beginning design pedagogy. Challenges caused by abstraction for both pedagogy and beginning design students are investigated. Arnhem's definition of abstraction as relations between part and whole implies a pedagogical approach for learning design that positions encounters with abstraction as a transformative threshold, suggesting that a gradual introduction of abstraction can build connections through embodied experience rather than disassociations. A series of architectural design exercises will be demonstrated that are structured, as result of this study, to gradually introduce abstract operations in design through a progressively transforming sequence over the first six weeks of beginning design studio. Delivered as analogous to architecture, each successive exercise initiates an abstract design operation as an individual design choice, enabling students to learn to see part in terms of whole, toward a working, conceptual understanding of abstraction in design.
\end{abstract}

Keywords: Beginning Design Pedagogy; Abstraction in Design; Threshold Concepts of Learning; Design Learning Theory; Transformative Learning; Architectural design.

\section{Introduction}

Almost all beginning design exercises investigate architecture through a pedagogy taken-for-granted by its instructors, by immediately asking the student to work abstractly. The beginning design student is not only not ready for abstraction, they do not understand abstraction's mechanisms of transformation, nor how abstractions become active within a design processes they are only just starting to comprehend. To abstract something is to draw it out of the concrete, and unless a student is looking for this displacement, they will become disconcerted, struggle, and become lost to the design process. Abstract operations of design process, when presented out of step with student selfdevelopment, can mislead and distort experience, interfere with the transformative learning necessary to design education, and ultimately malign the meaning of the designed environment. 
This essay will define and explore the act of abstraction as a threshold concept within the transformative journey of design student selfdevelopment, first by defining abstraction through the writings of Sigfried Gidieon and Rudolph Arnheim. Also examined will be assumptions about abstraction as a threshold concept in beginning design pedagogy, as well as the associated challenges caused by abstraction for both pedagogy and beginning design students. In particular, Rudolph Arnhem's definition of abstraction as a relationship between part and whole suggests a pedagogical approach for learning design that positions abstraction as transformative of learning. A duly considered pedagogical introduction of abstraction can build connections through embodied experience to a deeper understanding of abstraction in design processes. A series of initial design exercises will be demonstrated that model design processes in such a progressively transforming sequence over the first six weeks of beginning design studio. Delivered as discreet analogies of the architectural environment, each successive exercise necessitates initiation of an abstract operation of transformation as an individual design choice, enabling each student to learn to see part in terms of whole, toward building a conceptual understanding of abstraction in design processes.

\section{Abstraction as a Threshold Concept in Learning Design}

Learning design involves a developmental transformation of the learner, especially with respect to the frequently confounding elements encountered in learning design. For beginning design students to make informed decisions on design exercises requires development of an awareness of the source and context of their knowledge, as well as their values and feelings, within a context that enables testing and critical reflection of the validity of these assumptions.

"Transformative learning refers to the process by which we transform our taken for granted frames of reference (meaning perspectives, habits of mind, mind-sets) to make them more inclusive, discriminating, open, emotionally capable of change, and reflective so that they may generate beliefs and opinions that will prove more true or justified to guide action. Transformative learning involves participation in constructive discourse to use the experience of others to assess reasons justifying these assumptions, and making an action based on the resulting insight." [Mezirow 2000, 7-8]

The necessity for these transformations in the beginning design student is evident in consideration of frequent student reliance on pre-conceptions in early design exercises. As Mezirow states, transformative learning occurs when students become critically aware of their own tacit assumptions amid those of others when assessing their relevance. [Mezirow 2000] Transformative learning in design thinking involves an acknowledgement that pre-conceptions must metamorphoze in order to become usefully relevant. This kind of transformation in the learner can be characterized as an encounter with a threshold concept. As explicated by Michael Tovey,

"The threshold concept theory posits the idea that within disciplines there are conceptual gateways or portals, which - due to their troublesome nature - can make it difficult for students to progress. This notion of a threshold concept is seen as distinct from 'core concepts' - or building blocks - within disciplines, as it engages with the notion of transformation. Grasping, experiencing and understanding a threshold concept will irrevocably transform a student's understanding, and this transformation can relate to the particular subject at hand, and or be extrapolated beyond the academy." [Tovey 2016, 10-11]

There are many such threshold concepts encountered as students learn to design in their initial design studios. A little recognized threshold concept in design learning is the confrontation with abstraction in the form of drawing, modeling, and design operations, especially when creative and/or conceptual design thinking is initially called for. 


\section{The Threshold of Abstraction in Design Learning}

Architectural designers imagine the world by use of design activities using drawings, models, and diagrams as instruments of production and communication but also as a means of anticipating how we experientially situate ourselves in the world through engagement of body, mind, and imagination. Architectural design utilizes of these kinds of representations, as abstractions of the form and construction of buildings, and simultaneously to imaginatively visualize spatial and social experience. [Sweeting 2011]

The term, 'abstraction' as used in this essay does not a refer to an aesthetically abstract appearance but is instead concerned with processes of abstraction. Some definitions of abstraction will be explored as a means of describing its effect in design. Abstracting is a progressive transformation away from any concrete actuality drawn out of the concrete world as a continuum from the particular and sensorial to the general and even symbolic. [Seabury 1991] Sigfried Giedion defined abstraction as an active mechanism of transformation of physical reality in which there is a "distillation of the essential elements from an intangible multiplicity of forms." [Giedion 1962, 10] Giedion defines the act of abstracting as "withdrawal" from the particulars of an object in order to pick up its general essence out of the vast abundance of inputs available within perceptual attention. The act of abstracting also isolates one aspect of an object from all other aspects of the object in order to separate part from whole, this for the purposes of perceiving significance in relations between parts instead of subsuming them unto a greater whole. The complexity of particulars and relations is resolved for Giedion through the main tenant of Gestalt psychology - the whole is greater than the sum of its parts. Giedion finds that the concrete perception of a thing comes when "the parts are derived from the whole, which alone determines its character." [Giedion 1962, 14] Giedion's primary interest is in abstraction in art forms for the role it plays in which the everyday appearance of the subject is transformed by abstraction into symbolic essences. Abstraction thus occurs as a simplifying and distilling concentration of form within transparency, simultaneity, and movement. These effects, if abstractly withdrawn far enough from the actual, recognizes a signification of universals as "magical symbols" in which abstraction can become transcendent. [Giedion 1962, 24] Giedion's concern for abstraction is to describe the use of abstraction in the analysis of artistic production within a historical, anthropological, archeological context and does not refer to the means of production or the concerns of the producing artist. [Giedion 1962]

A later contemporary, Rudolph Arnheim, describes the act of abstraction as a removal, "since the verb abstrahere means to actively draw something away from somewhere and passively to be drawn away from something." [Arnheim 1969, 153] Arnheim articulates abstraction as an act of generalization, developing in abstraction a generative conceptual order, as "an act of restructuring through the discovery of a more comprehensive whole." [Arnheim 1969, 187] Arnheim views representation in acts of artistic production as an active and instrumental restructuring of the processes of abstraction in perception:

"Percepts are generalities from the outset, and it is by the gradual differentiation of those early perceptual concepts that thinking proceeds toward refinement. However, the mind is just as much in need of reverse operation. In active thinking, notably in that of the artist...wisdom progresses constantly by moving from the more particular to the more general." [Arnheim, 1969, 186]

Arnheim views representation and engagement in design as part of the same cognitive activities. However, students new to design thinking are unaccustomed to separating part from whole, or concentrating a distilled (abstract) view of experience, especially as an act of conceptualization. A more instrumental definition utilizing relations between part and whole is when abstraction is used as a technique 
to reduce the complexity of a problem by removing irrelevant properties while retaining the important ones necessary to still be able address a given problem. [Ponson 2010] A primary agent of transformation bound into design processes, abstraction becomes active as a reduction, simplification, and in the language of design, conceptualization. Information is lost in abstraction in the interest of conceptualization. To use abstraction as a transformative device within design, a designer must come to recognize its distancing effect from both physical reality and actual experience, and thereby the meaning of engagement in living experience, or as characterized by Juhani Pallasmaa, "the silent understanding that lies hidden in the human existential condition and our specific embodied mode of being," [Palassmaa 2009, 22]

\section{Abstraction as a Threshold Learning Experience}

Abstraction has continued to be a fundamental issue in design pedagogy due to traditions from Bauhaus and art-school pedagogies and curricular bias toward satisfying needs of more complex designing later in a curriculum. Learning to use abstraction as an instrument of design is also one of the most important threshold encounters in early design learning, encountered as students first engage abstract operations within iterative processes of design. Most students enter into design programs with a limited critical view of their experience in the world and only a vague, uninspected comprehension of abstract processes that bring about that world. Beginning design students are instead engaged in seeing the world through symbolic appearances rather than how things really are. The observer of appearances sees only wholes as a relationship to categories of prior experience as the thing known, instead of the characteristics of the thing itself. Perceiving the world becomes valued as part of symbolic reordering of the world as a personal, subjective venture. (Vesey 1976) A designer does not just manipulate the appearances of the designed world for purposes of symbolic engagement but is responsible for all the constituent qualities of material things that in the end are the subject of experience. Learning abstracting as a part of design thinking is disruptive and frequently becomes an ordeal for new students as they encounter abstraction's distancing from the real. This experience often leads to the undoing of personal meaning in experience. As students become untethered from their ontological anchorings, many become unable to realize the substance of first design experiences.

Abstracting from the actual content of both architecture and experience is potentially an advantage in mature design activities but it presents great difficulties to learning in beginning design pedagogy. However, beginning design pedagogy takes for granted that the abstracting of issues like 'form' from the wholeness of architecture is not natural to everyday experience, when in fact it is raising an encounter with the threshold of abstraction. While abstraction has the potential to enable the dissolution of preconceptions about architecture, abstraction instead confounds those prior conceptions that might otherwise be drawn out of the experience of the world, leaving only ungrounded abstractions in its place.

In student experience of design pedagogies, issues like 'form' often become an abstraction in-itself, leaving an impression that architecture should look and act abstractly. The 'form' of architecture does not operate in experience separate from myriad other aspects of the surroundings that influence the constitution of experience. Architectural design pedagogies that overly stress abstract process place abstraction out of the developmental context of a student's movement through a design curriculum, devaluing experience with an impression that abstraction, not the building itself, is the substance of design. If abstraction is presented without connection to its origins, students can be led to the idea that architectural activity is principally only a mental operation of thought. With little development of heuristic mechanisms to help them design, or any measure of the awareness of the difference between representation, appearances, and reality, beginning design students have trouble 
navigating cognitively from concrete to abstract thinking to begin to construct operational design structures to manage the abstract components of design processes. Instead, when recognized as a threshold learning experience, encounters with abstraction in beginning design learning experiences can provide an opportunity to reveal abstract transformative operations as a reduced aspect of architecture that can be clearly grasped, experienced, and understood.

\section{A Series of Design exercises that Engage the Threshold of Abstraction}

The role of the threshold of abstraction in design student development is commonly overlooked or assumed in design pedagogy and curriculum, often in favor of disciplinary traditions or uninspected faculty preferences for their own beginning design experiences. Without a pedagogy presenting a clear understanding of abstraction and its operations in design processes, students are left on their own to 'get it' or figure it out for themselves later in the curriculum. To the contrary, it is an obligation of beginning design pedagogy to place students into such 'troublesome' design situations where threshold issues like abstraction can be encountered, explored, and comprehended as transformations of learning. Beginning studio exercises that stage encounters with threshold concepts offer comprehension of abstraction and transformation of preconceived notions of design in the context of critical discourse of the work of others. However, the encounter with the threshold of abstraction cannot be realized within a single design exercise. Just as abstraction is drawn from reality in stages of transformation, grasping the operations of abstraction on design learning best occurs in slow, deliberate transformations of the seeming concreteness of everyday experience in which students are comfortable.

In realizing a more gradual engagement with abstraction, the initial six-week project was structured into a progressive sequence of exercises drawn out of the architectural environment but are not representational.
Differing yet concise abstract operations transform each preceding iteration to progressively engage greater degrees of issues like geometry, volume, space, mass, frame, and panel. Each successive stage necessitates design choices made by each student to comprehend and initiate each abstract operation of transformation, as a means of developing a personal stake in that stage and in the role of abstract operations through the entire process. In applying each abstract operation in relation to previous iterations, students learn to see part in terms of whole, while also learning not to be deterministic about the next steps. Making design decisions always with respect to a previously transformed iteration enables a conceptual understanding of the abstracted nature of architectural form.

The exercises are hands-on design learning experiences, engagement that necessitates execution in direct resolution of idea/concept and material. In hands-on efforts, flaws in making are clearly exposed, often as a direct critique of a concept materialized through design thinking and also when compared to other students solutions. As stated by Robert McCarter, hands-on design exercises operate to, "bind together thinking and making, engaged and embodied in the action of building." [McCarter, in McKay-Lyons, 2008] Hands-on exercises place the student directly into the role of designer, with process and result of decisionmaking bound up in thinking and making, and in comparative project review.

Exercise 1 - First in the sequence of exercises happens on the first day of the initial design studio course. Given a three-foot piece of tiewire and a rock, students are told to make an 'orderly support for the rock.' Using no tools other than the hand, the rock must be one 'fist' from the table surface. (Figure 1) Critique of this project is focused on motives for design decisions, play, conceptualization, and workmanship. The second aspect of the project is to transform the concept of the project by using paper, with no glue, instead of wire. It is made clear in project review that material 
transformation is an abstract operation. [Temple 2009]
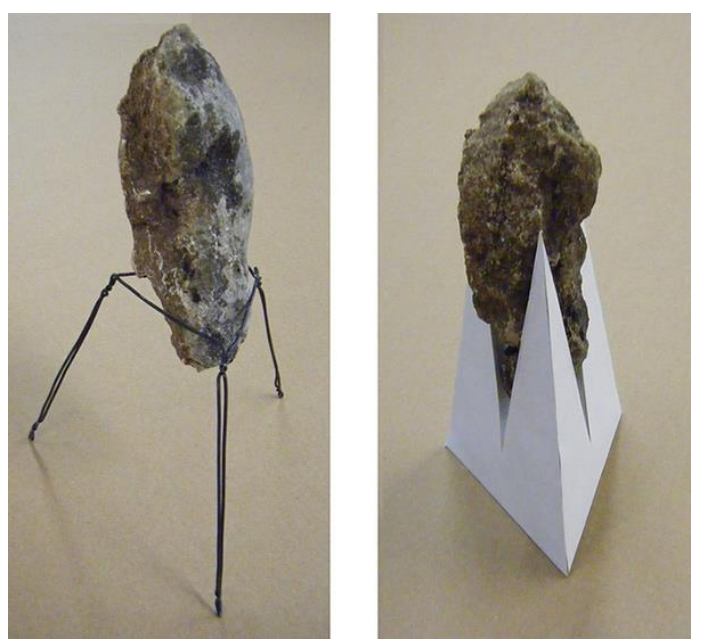

Figure 1. Ex. 1-Place for a Rock.

Exercise 2 - Students are asked to make a drawing of the paper place for a rock exercise as the first step in the next transformation. Most have limited drawing skills and draw a portrait of the project (not shown). The "Bull Profile Series" (1973 not shown) by artist Roy Lichtenstein is an example of abstract transformation from a drawing of only a figure to the figure abstracted into the geometry of the
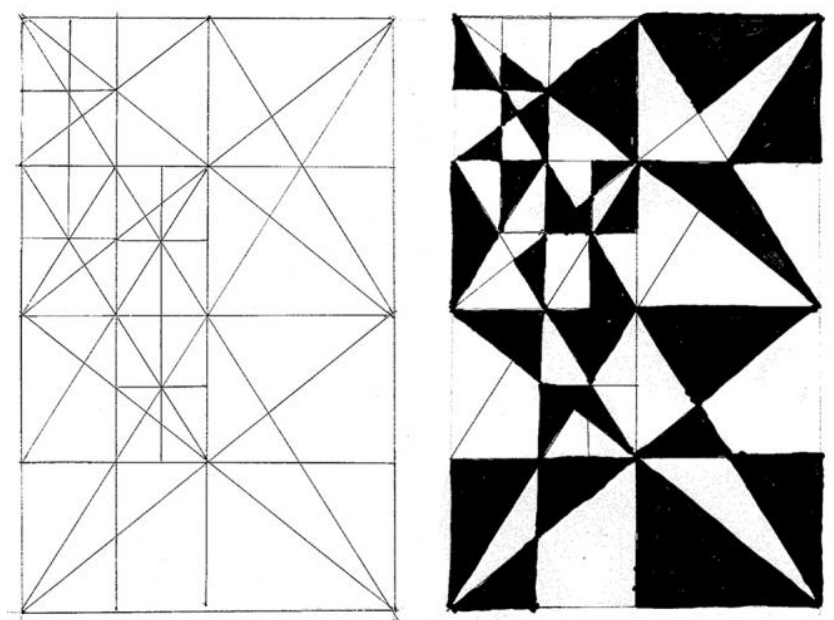

Figure 2. Ex 2-3D to 2D transformation

rectangular drawing field. The final stage of this transformation asks students to make choices in darkening every other geometric space to produce a black and white value drawing. Review points out that this project is analogous to analyzing a site and using geometric regulation in developing plans and elevations.
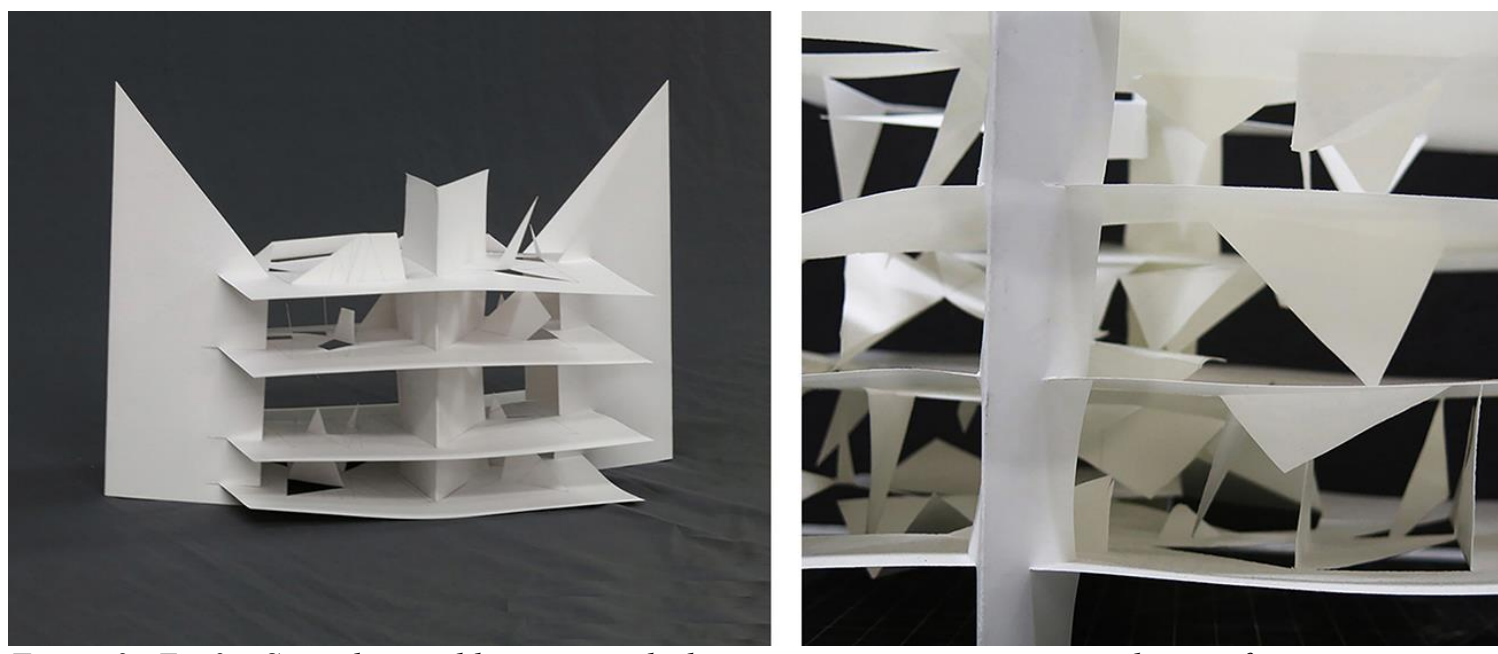

Figure 3. Ex. 3-Spatial assembly using stacked, cut-out geometric patterns and view of interior space 


\section{Journal of}

\section{Design Studio}

Exercise 3 - The 2 dimensional geometric transformations represented in the geometry of the value drawing are first cut-and-folded into a relief regulated by the geometries. Four cut-and folded-layers are stacked and separating supports are designed regulated by the

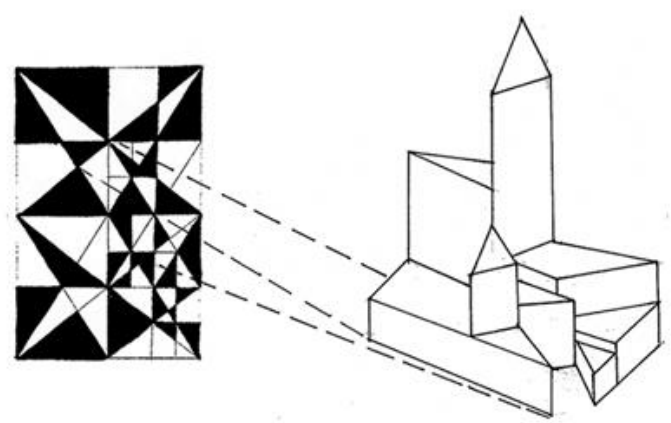

wooden sticks to capture the space of the solid form. (Figure 4) Wood construction provokes understanding of workmanship and joinery as significant to architectural form. A lecture follows showing steel frames and other buildings using these components.

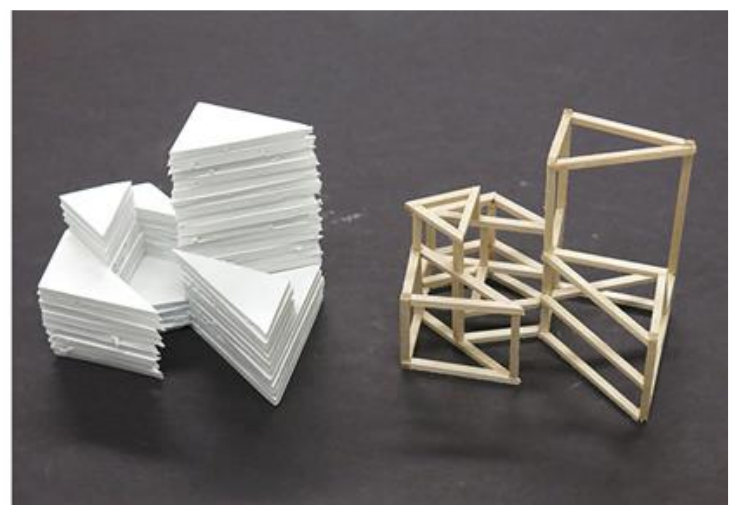

Figure 4. Ex 4 \& 5. Transform into layered solid, followed by material transform (in wood)

extension of internal geometries. Students hold the constructions up to their eyes and use their cameras to photograph and film the interior spaces. A lecture compares the resultant construct to existing buildings like the Herzog $\&$ de Mueron Miami parking garage.

Exercise $4 \& 5$ - The second sequence of exercises begins by abstractly developing a portion of the geometries of the value drawing by stacking geometrically derived layers into a 3-diimensional solid, which becomes an example of the relations between mass and space in architecture. The second abstract operation is a material transformation using
Final Exercise: Preliminary - The beginning of the final sequence of exercises requires pouring two plaster blocks in a volume of 2" x 3" x 2 " high, regulated by rectangular and diagonal lines on a 1" module. The two different plaster bocks are then placed in alternate arrangements to observe formal and spatial variations by constructing tacit spaces around and between them due to formal variants in the blocks. In review, these various arrangements present an analogy to the manner in which building masses construct spaces. All plaster forms are arranged into streets and city blocks to develop relations to scale.
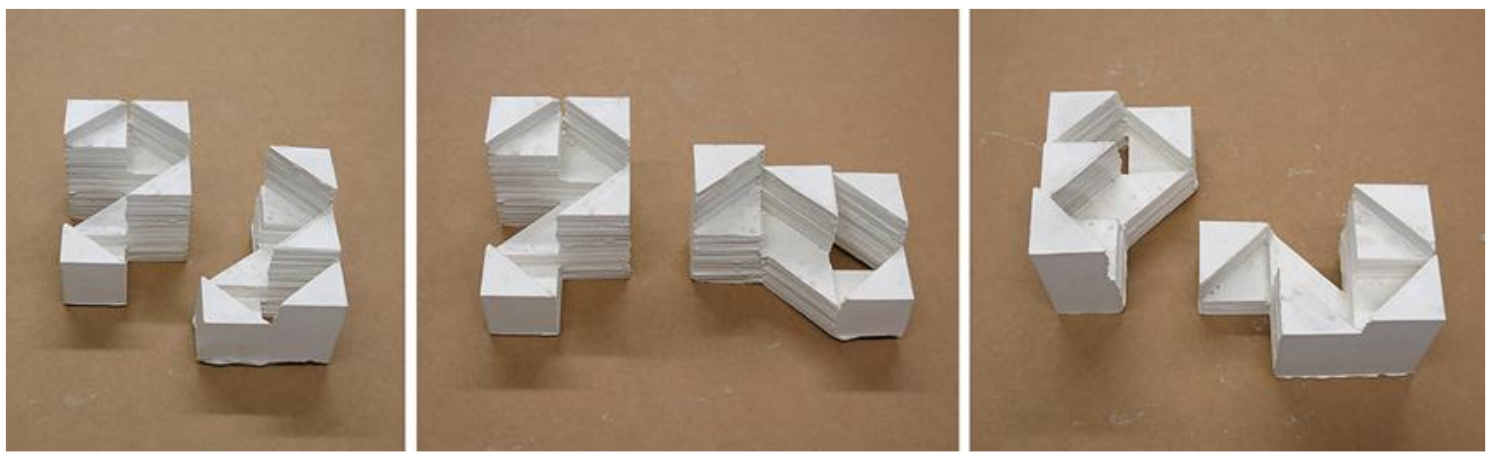

Figure 5. 2" x 3" x 2" high plaster blocks in three alternate spatial arrangements 

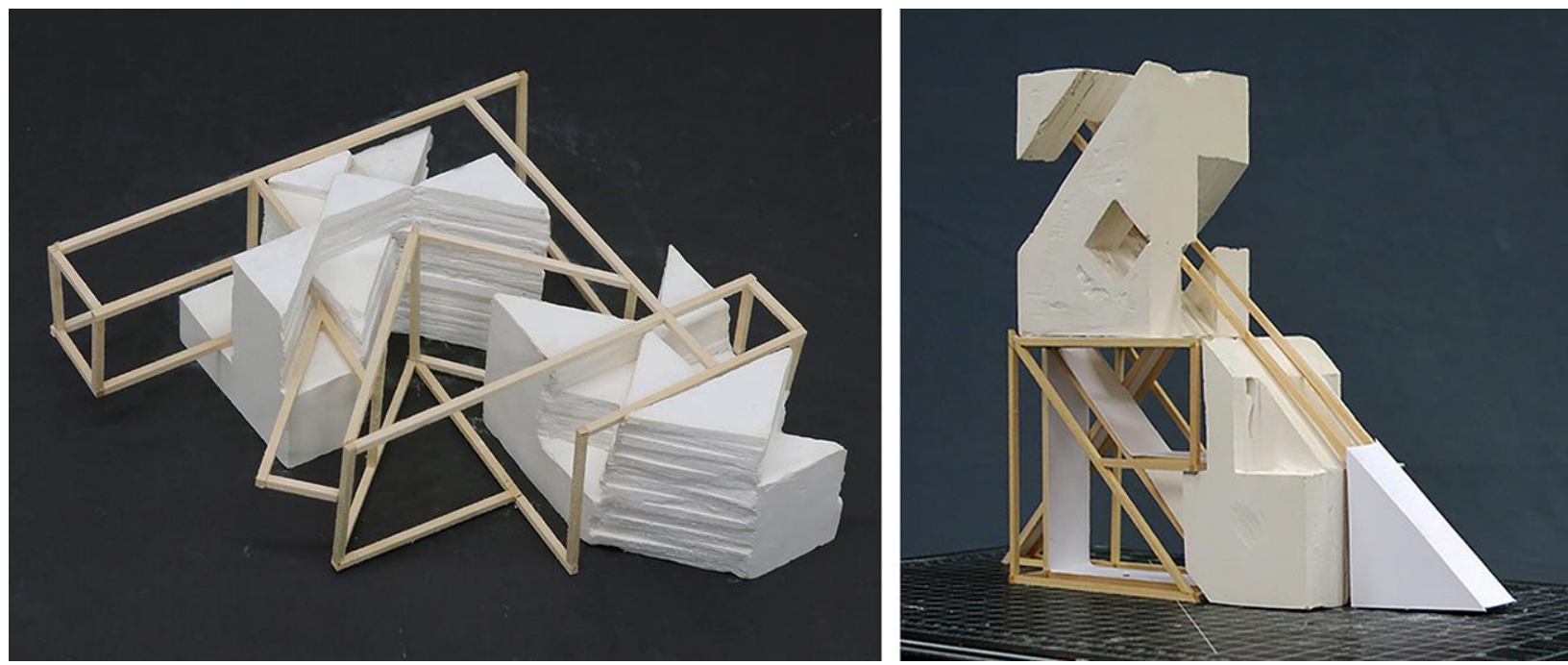

Figure 6. System of mass, frame, and space. Left-blocks frame added. Right-blocks at eye-level with frame and panels added

Final Exercise - Exercise parameters ask for design of a 'system of mass, frame and space,' by adding wooden frames to amplify the spatial development of the entire form as implied by the arrangement of the plaster blocks (Figure 6). Another transformation asks students to add panels to the system to emphasize and transform the spatial nature of the plaster and wood construction. Students clearly recognize that these components act systematically like mass, and frame, and panel systems in building design. Students are required to photograph the final construction both as an object and as at a simulated eye-level scale. This photographic process transforms the construction from an abstract object into an experientially scaled conceptualization of a building. A final lecture compares the resultant constructions to existing architectural designs.

\section{Discussion and Implications of The Threshold of Abstraction}

Students recognized the progressive abstract transformation in realizing their final work was derived from the exercise of the first day. This recognition acknowledges that the iterative, developmental process of creative design thinking in the entire sequence was analogous to design, especially regarding the transformative nature of abstract operations amid their own transformation as designers. Despite direct representation not being part of the exercises, students worked readily with abstracted geometric regulation, illusions of depth and layering, mass, space, and frame as 'stand-ins' for components of actual architecture. Because the exercises in form were framed as analogous to architecture, student design decision-making about these issues occurred without interference from issues raised in the fullness of architectural experience. Critical to student navigation of the threshold of abstraction was a realization they can switch back and forth between perceptions of the object as thing and scaled model. As a hands-on construct analogous to the way that architecture acts in full-scale, the applied knowledge in making these exercises was readily absorbed as a conceptual design foundation.

Working with form distilled abstractly from architecture asks the beginning design student to work abstractly with little understanding that form is being used as a pedagogical artifact of architecture. Abstractions stand for other things, ideas, or perceptions, and as such, can create distance that reduces experience only to thought, far from the fullness of experience. A primary difficulty in learning to design happens when abstraction is taken as different from reality, rather than its connection to reality. An idea that interaction with architectural design happens abstractly, mentally, with little 
association with the actual concrete reality of architecture in experience leads to design thinking that disassociates architectural design decision making from responsibility toward the fine-grained complexity of experiential, socioicultural, environmental, and material forces.

Abstraction is a central issue of beginning architectural education because coming to terms with abstraction is an early demand of learning design, with the intention that students learn new modes of abstract representation as instruments of design process, to see the world through abstraction, to think through abstraction, and use it to communicate an imagined architecture. [Sweeting 2011] Beginning design pedagogy must recognize the challenges beginning design students experience in coming to terms with how abstraction becomes operational as a threshold concept of learning. Because most students enter beginning design education unfamiliar with abstraction and with ineffective abilities to think or work abstractly, beginning designers need to be gradually drawn toward abstraction in a period of acclimation, in opposition to the way abstraction draws away from actuality, to retain its essential groundedness in the real. As a threshold concept, learning is transformed by comprehension that abstracting the world opens up new interpretations, possibilities, and range of content. However, it also conflicts with each student's previously known, comfortable, yet uninspected way of seeing the world that, instead of giving clarity, tends to be experienced as an unwarranted initiation of confusion.

Curriculum design is often thought of as an orderly presentation of core disciplinary concepts, within an increasing complexity from foundation to discipline-specific levels correlated with movement through sequences of courses. Threshold concepts however, are distinct from 'core concepts' of a discipline, as threshold concepts engage with transformations of learning while disciplinary concepts do not necessarily do so. Beginning students are novice learners who grow into advanced novices at the second level, but are in no way thought to be developing expertise. [Perry 1998] Developmental learning theories suggest that initial experiences in a college curriculum that are direct and experiential in nature are most consistent with student learning maturity level. [Perry 1999] However, encountering abstraction too early in a student's development can prioritize abstraction outside of readiness to work in this manner. At the beginning of a design curriculum, curricular concern for student development must be much greater than the conveyance of disciplinary concepts because of the need for learning experiences that transform student development. The sequence of exercises presented in this essay serves as a threshold for the recognition of processes, abstract operations, and the opening of ideas that transform student learning, making beginning design students more receptive to and mindful of their own design inquiries.

Realization of intellectual boundaries and recognition of new potentials is part of the educational process inherent in discovering the operative nature of abstraction in design. Within the educational structure, limitation to the abstraction of an issue like form can seem a well-reasoned, strategic pedagogical reduction to just the amount of content with which a beginning design student can grapple. However, first design experiences must present abstraction in a manner that enables students to both accept its abstract distance from actuality and to learn to think by way of its artifice while hindering misplaced notions that abstraction initself can result in complete architectural proposals. The basic value of beginning design pedagogy as a foundation of a design curriculum is not to teach students what or how to think, rather it is in teaching them to value thinking through creative processes and that this thinking must become disciplined and spring from an enabled sense of self-development.

\section{References}

Arnheim, R. (1969). Visual Thinking. Berkeley CA: University of California Press. 
Giedeon, S. (1962). The Eternal Present: 1. The Beginnings of Art, 2. The Beginnings of Architecture. New York: Bollingen Foundation.

Hoare. Carol (Ed). (2006) Handbook of Adult Development and Learning. Oxford, UK and New York: Oxford University Press.

Land, Ray, and Cousin, Glynis, Meyer, Jan H.F. Davies, Peter. (2006) "Implications of Threshold Concepts for Course Design and Evaluation." in Overcoming Barriers to Student Understanding: Threshold Concepts and Troublesome Knowledge. By Meyer, Jan H.F. and Land, Ray (Eds), London and New York: Routledge, 2006.

Lawson, Bryan. (2019) The Design Student's Journey: Understanding How Designer's Think. New York and London: Routledge.

McCarter, Robert, (2008) quoted in McKayLyons, "Ghost: Building an Architectural Vision" Princeton Architectural Press, 193.

Meyer, Jan H.F, and Land, Ray, and Baillie, Caroline (Eds) (2010) Threshold Concepts and Transformational Learning. Rotterdam, Netherlands: Sense Publishers.

Mezirow, Jack. (2000) Learning as Transformation: Critical Perspectives on a Theory in Progress. San Francisco, CA: JoseyBass: A Wiley Company.

Osmond, Jane and Turner, A. The Threshold Concept Journey in Design: from Identification to Application. in Jan H.F. Meyer and Ray Land and Caroline Baillie (Eds). Threshold Concepts and Transformational Learning (pp: 347-364). Rotterdam: Sense Publishers.

Perry, W.G. Jr. (1998) Forms of Intellectual and Ethical Development in the College Years: A Scheme. New York: Jossey-Bass.

Ponson, Marc and Taylor, Mathew E Taylor and Tuyls, Karl. (2010) "Abstraction and Generalization in Reinforcement Learning: A Summary and Framework," in Adaptive Agents and Multi-Agent Systems IV, LNAI, SpringerVerlag, 1-33.

Seabury, Marcia Bundy. (1991) Critical Thinking via the Abstraction Ladder. The English Journal Vol 80 No. 2. National Council of the Teachers of English, 44-99.

Sweeting, B. (2011). Conversing with Drawings and Buildings: from Abstract to Actual. Kybernetes Vol 40 No 7/8, 1159-1165.

Temple, Stephen. (2009) Initializing the Discipline of Design in the First Project(s). Proceedings of the National Conference on the Beginning Design Student, Louisiana State University, Baton Rouge LA: College of Art and Design, 207-214.

Tovey, Michael, and Osmond, Jane. (2014) Design Pedagogy and the Threshold of Uncertainty. International Conference of Engineering and Product Design Education. The Netherlands: University of Twente.

Tovey, Michael (Ed.) (2016) Design Pedagogy: Developments in Art and Design Education. London and New York: Routledge.

Vesey, Vesey, Godfrey N.A. 1965. "Seeing and Seeing As." In Perceiving, Sensing, and Knowing edited by R. J. Swartz, 68-84. Berkeley CA: University of California Press. 